\title{
Spontaneous rupture of the pancreatic
} arcade artery caused by neurofibromatosis type 1 successfully treated using emergency transcatheter arterial embolization, partial intra-aortic balloon occlusion, and stent graft placement: a case report and review of the literature

Ryo Morita ${ }^{1,3^{*}}$ D, Daisuke Abo', Takeshi Soyama', Yuki Yoshino', Toru Yoshikawa', Tasuku Kimura² and Kohsuke Kudo ${ }^{1,3}$

\begin{abstract}
Background: Vascular abnormalities in neurofibromatosis type 1 (NF1) are rare, but are the second leading cause of death in persons with NF1. In NF1 vasculopathy (NF-V), fatal bleeding due to a spontaneous arterial rupture sometimes occurs. Ruptured extracranial arteries in patients with NF1 often involve thoracic vessels, such as the intercostal and subclavian arteries; very few reports exist regarding the abdominal region. Herein, we present the first case of intraperitoneal bleeding due to spontaneous pancreatic arcade artery (PAA) rupture associated with NF1, successfully treated by transcatheter arterial embolization (TAE) combined with stent-graft placement and partial intra-aortic balloon occlusion (IABO).

Case presentation: A 40-year-old woman complained of back and abdominal pain. Upon admission, her blood pressure was $85 / 41 \mathrm{mmHg}$ and heart rate was 129 beats/min. Computed tomography (CT) showed large intraperitoneal bleeding due to PAA rupture. After CT scanning, her systolic blood pressure decreased to 50 $\mathrm{mmHg}$. Therefore, we performed emergency TAE with partial IABO. She was treated by TAE of the anterior superior pancreaticoduodenal artery, anterior inferior pancreaticoduodenal artery, and inferior pancreaticoduodenal artery. However, even after TAE, minor extravasation around the superior mesenteric artery continued, and her vital signs remained unstable. Stent-graft placement was selected to stop the haemorrhage, preserving normal blood flow of the superior mesenteric artery trunk. Excellent patency of the stent graft was confirmed on follow-up CT, and she was discharged on postoperative day 56.

(Continued on next page)
\end{abstract}

\footnotetext{
* Correspondence: ryo561201@me.com

'Department of Diagnostic and Interventional Radiology, Hokkaido University

Hospital, Sapporo, Japan

${ }^{3}$ Department of Diagnostic Imaging, Hokkaido University Graduate School

Medicine, Hokkaido University, Sapporo, Japan

Full list of author information is available at the end of the article
}

Springer Open

(c) The Author(s). 2020 Open Access This article is licensed under a Creative Commons Attribution 4.0 International License, which permits use, sharing, adaptation, distribution and reproduction in any medium or format, as long as you give appropriate credit to the original author(s) and the source, provide a link to the Creative Commons licence, and indicate if changes were made. The images or other third party material in this article are included in the article's Creative Commons licence, unless indicated otherwise in a credit line to the material. If material is not included in the article's Creative Commons licence and your intended use is not permitted by statutory regulation or exceeds the permitted use, you will need to obtain permission directly from the copyright holder. To view a copy of this licence, visit http://creativecommons.org/licenses/by/4.0/. 
(Continued from previous page)

Conclusion: PAA rupture associated with NF1 can be successfully treated by TAE combined with partial intraaortic balloon occlusion, and stent-graft placement.

Keywords: Neurofibromatosis type 1, Stent-graft placement, Endovascular therapy, Pancreatic arcade artery, Spontaneous rupture, Vasculopathy, Intra-aortic balloon occlusion

\section{Background}

Vascular abnormalities in neurofibromatosis type 1 (NF1) are rare, with an incidence of $0.4-6.4 \%$ (Raborn et al. 2020); however, fatal bleeding can occur due to a spontaneous arterial rupture. NF1 vasculopathy (NF-V) is the second most common cause of mortality (Rasmussen et al. 2001). Among 19 cases of ruptured extracranial arteries in NF1 reported from 1996 to 2016 (Huffman et al. 1996; Ishizu et al. 2006; Hinsch et al. 2008; Aizawa et al. 2010; Falcone et al. 2010; Hung et al. 2012; Park et al. 2012; Moerbeek et al. 2015; Liang et al. 2016), the most common bleeding sites comprised thoracic vessels, such as the intercostal, subclavian, and internal thoracic arteries. Only two ruptures of visceral arteries (superior mesenteric artery (SMA) trunk and renal artery) have been reported (Huffman et al. 1996; Hinsch et al. 2008). As yet, none have involved a spontaneous rupture of the pancreatic arcade artery (PAA). Herein, we present the first case of intraperitoneal bleeding due to spontaneous PAA rupture associated with NF1, successfully treated by transcatheter arterial embolization (TAE) combined with stent-graft placement under partial intra-aortic balloon occlusion (IABO).

\section{Case presentation}

A 40-year old woman, diagnosed with NF1 complained of acute, severe back and abdominal pain during work. She was transferred to the emergency room at our hospital due to syncope. Upon admission, her blood pressure was $85 / 41 \mathrm{mmHg}$ and heart rate was 129 beats/ min. Computed tomography (CT) showed a large retroperitoneal hematoma, with extravasation around the duodenum, and intraperitoneal blood (Fig. 1a,b). After CT scanning, her systolic blood pressure decreased to $50 \mathrm{mmHg}$. Laboratory data revealed severe anaemia (haemoglobin, $5.4 \mathrm{mg} / \mathrm{mL}$ ) and mild coagulopathy (prothrombin time-international normalized ratio, 1.31; activated partial thromboplastin time, $41.0 \mathrm{~s})$. No thrombocytopenia (platelets, $225 \times 1000 / \mu \mathrm{L}$ ) and no history of anticoagulant therapy were noted. Her blood pressure was only slightly increased to $70 \mathrm{mmHg}$ by a rapid infusion of packed red blood cells (two units); thus, an intra-aortic balloon (Rescue Balloon ${ }^{\circledR}$-ER, Tokai Medical Products, Inc., Aichi, Japan) was introduced via the left femoral artery, and balloon was partially inflated at the lower level of the thoracic aorta to stabilize her systemic blood pressure. Because we suspected a PAA rupture associated with NF1, based on CT findings (Fig. $1 \mathrm{c}, \mathrm{d})$, emergency TAE of the PAA was planned shortly thereafter.

After the introduction of a 5-F sheath via the right femoral artery, celiac arteriography was firstly performed, which showed extravasation from the anterior superior pancreaticoduodenal artery (ASPDA), as well as its disruption (Fig. 2a).

Because isolation of the pseudoaneurysm was difficult due to the disruption of the ASPDA, the ASPDA was embolized from the disrupted site to a healthy segment with five pushable platinum coils $(2.0 \mathrm{~mm}$ diameter with $60 \mathrm{~mm}$ length, C-stopper coil, Piolax Medical Devices Inc., Kanagawa, Japan), using a 1.7-F coaxial microcatheter (ASAHI Veloute, Asahi Intecc Co., Aichi, Japan) advanced through a 4-F Mikaelson catheter (Fig. 2b). Aiming to isolate the disrupted PAA completely, angiography of the SMA was subsequently performed, which showed a huge pseudoaneurysm and extravasation of the anterior inferior pancreaticoduodenal artery (AIPDA), as expected. In addition, rupture of the posterior inferior pancreaticoduodenal artery (PIPDA) was also suspected, but was not definite (Fig. 3a). At this time, her blood pressure was still unstable. The catheter and sheath were changed to a 5.2-Fr balloon catheter (Selecon $\mathrm{MP}^{\bullet}$ balloon, TERUMO, Tokyo, Japan) and J-shaped sheath (Medikit, Tokyo, Japan) for temporal selective occlusion of the SMA (to stabilize the bleeding from the SMA), rather than a complete IABO. Selective catheterization via a microcatheter advanced through an inflated 5.2-Fr balloon catheter was difficult due to the steep angles of the PAA (both the AIPDA and PIPDA); thus, after several attempts, the microcatheter was changed to a 2.4-F steerable microcatheter (SwiftNINJA, Sumitomo Bakelite, Tokyo, Japan). A huge pseudoaneurysm of the AIPDA with early visualization of the portal vein, indicating an arterioportal fistula (Fig. 3b), was embolized with three detachable microcoils $(2.0 \mathrm{~mm}$ diameter with 60 mm length, Target ${ }^{\oplus}$ Detachable Coils; Stryker Corporation, Kalamazoo, Michigan 49,002, USA) from the disrupted site to a healthy segment, as with the ASPDA. However, complete haemostasis was not obtained by coil embolization alone (Fig. 3c). Therefore, we added a 1:1 


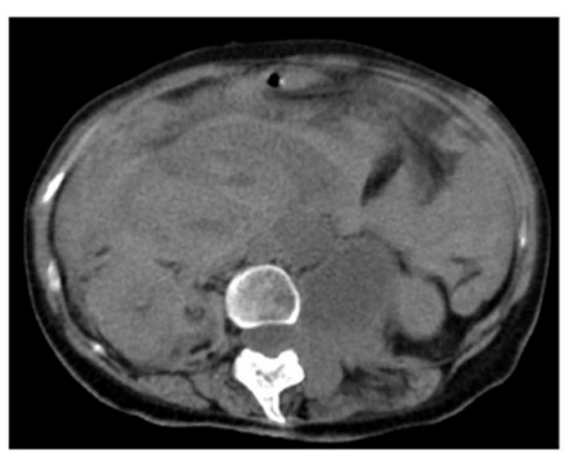

a.

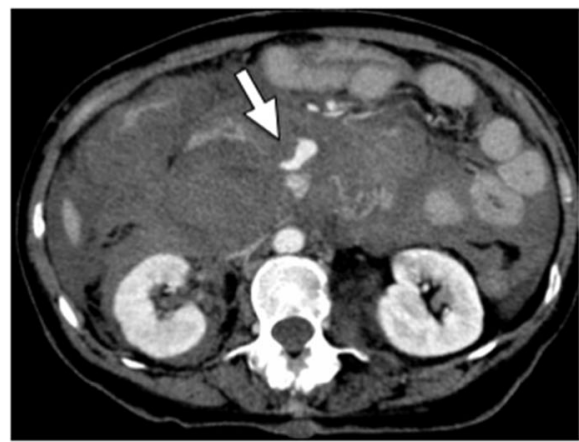

C.

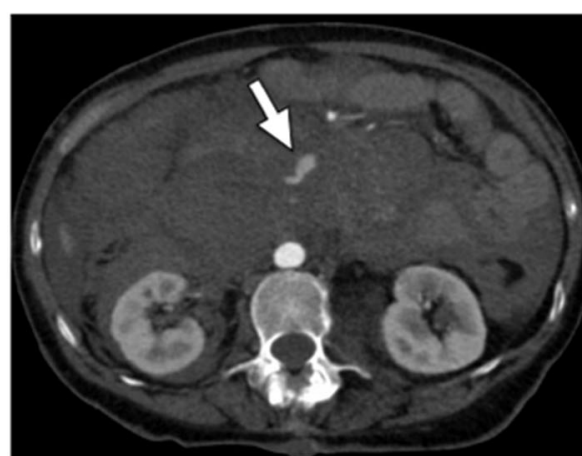

b.

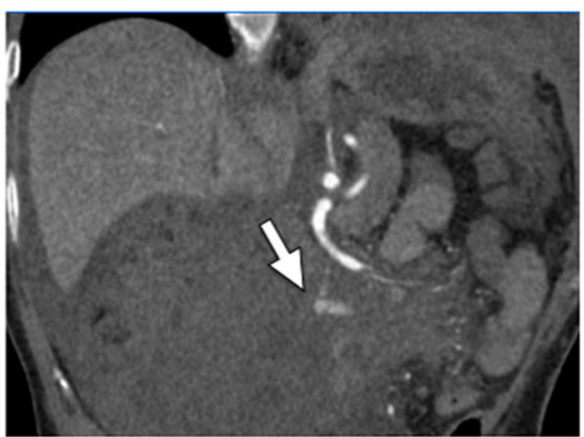

d.

Fig. 1 Computed tomography (CT) at symptom presentation. a Non-contrast-enhanced CT image showing a large retroperitoneal hematoma around the duodenum and haemorrhagic ascites. $\mathbf{b}$ Contrast-enhanced CT arterial phase image showing a large retroperitoneal hematoma with definite pseudoaneurysm (white arrow). c Contrast-enhanced CT portal venous phase image showing a large retroperitoneal hematoma with definite pseudoaneurysm (white arrow). d Contrast-enhanced CT arterial phase coronal images (slab-maximum intensity projection) showing the superior mesenteric artery (SMA) and pseudoaneurysm

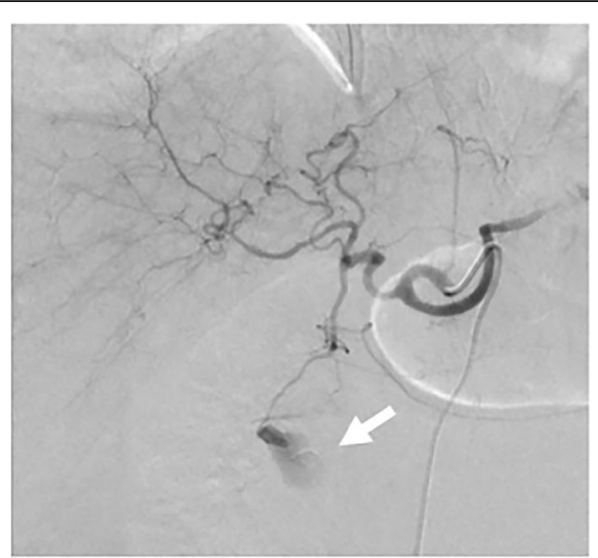

a.

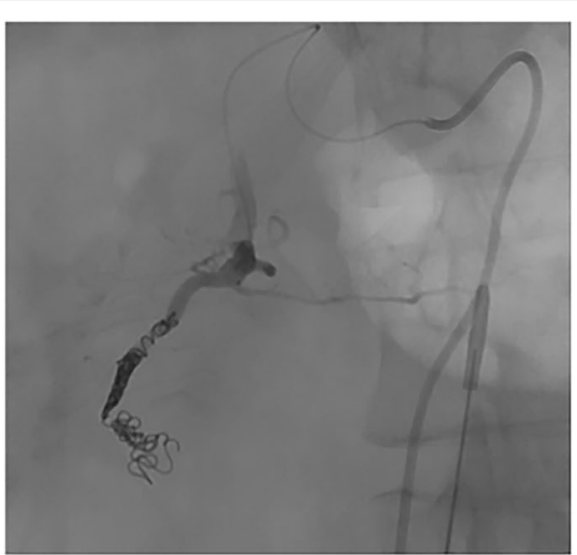

b.

Fig. 2 Celiac artery angiography at emergency transarterial embolization (TAE). a Celiac artery angiogram showing extravasation (white arrow) from the ASPDA, and its disruption. In addition, no median ligament compression syndrome was noted. $\mathbf{b}$ Digital angiogram, obtained after TAE of the ASPDA, showing a pseudoaneurysm, and the disappearance of extravasation from the celiac artery system. The ASPDA appears to be dilated, because a severe vascular spasm due to haemorrhage was relieved after TAE. ※ ASPDA: anterior superior pancreaticoduodenal artery 
a.

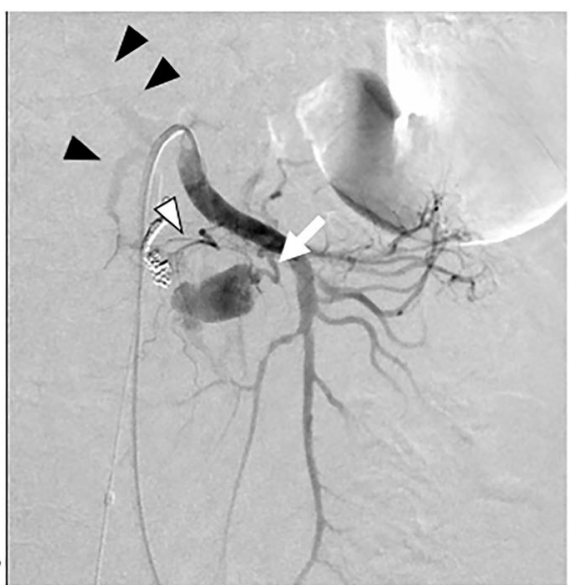

C.

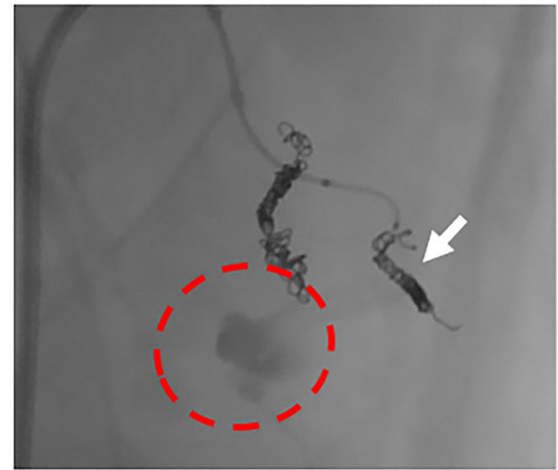

b.

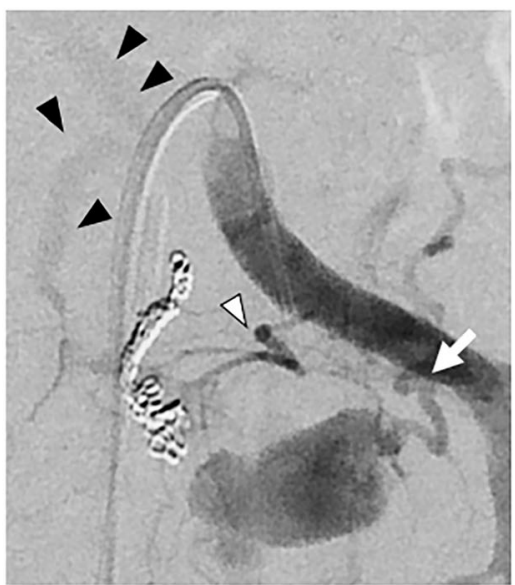

d.

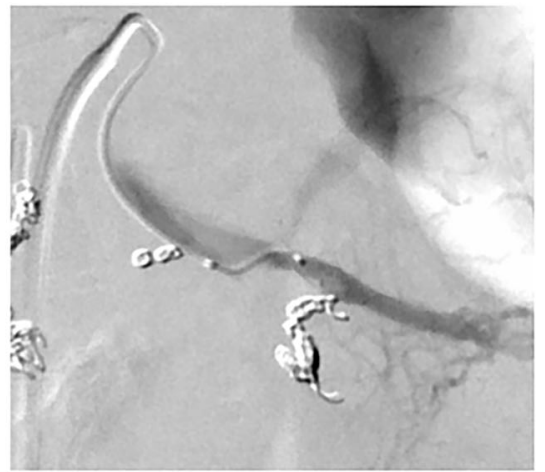

Fig. 3 SMA angiography at emergency transarterial embolization (a) (b) SMA angiogram showing a rupture of the AIPDA (white arrow) and early visualization of the portal vein (black arrowheads). The PIPDA (white arrows) was suspected to be involved in the haemorrhage. c Digital angiogram, obtained after coil embolization of the proximal AIPDA (white arrow), showing continued extravasation (red circle) from the AIPDA. $\mathbf{d}$ AIPDA angiogram after 50\% NBCA lipiodol injection to the AIPDA, showing the disappearance of extravasation, with maintained normal blood flow in the branch of the SMA near the AIPDA. ※ AIPDA: anterior inferior pancreaticoduodenal artery ※ PIPDA: posterior inferior pancreaticoduodenal artery. ※ NBCA: n-butyl-2 cyanoacrylate. ※ SMA: superior mesenteric artery

mixture of n-butyl-2 cyanoacrylate (NBCA; Histoacryl Blue; B. Braun, Melsungen, Germany) and iodized oil (Lipiodol; Guerbet, Aulnay- Sous-Bois, France). Complete flow stasis was achieved and the disrupted anterior PAA was isolated successfully. There was no overflow of glue into the SMA (Fig. 3d). The PIPDA was embolized by gelatin sponge particles, followed by two detachable microcoils (1.5 mm diameter with $30 \mathrm{~mm}$ length), as selective angiography of the PIPDA showed multiple minor bleeding sites via tiny its branches.

However, even after complete TAE of the PAA, minor extravasation around the main trunk of the proximal SMA continued, and her vital signs remained unstable (Fig. 4a). Because bleeding from the main trunk of the SMA or a fine vessel was suspected (radiologically not confirmed), stent-graft placement (Viabahn $7 \mathrm{~mm} \times 5$ $\mathrm{cm}$; Gore \& Associates, Inc., Flagstaff, AZ, USA) was selected to stop the haemorrhage and maintain the normal blood flow of the SMA trunk (Fig. 4b,c). Placement was performed using a 7-Fr guiding sheath (Flexor Tuohy-
Borst Side Arm Introducer, $55 \mathrm{~cm}$, Cook, Bloomington, IN, USA) and a stiff wire (V18, Boston Scientific, Marlborough, MA, USA). Extravasation completely disappeared immediately after stent-graft placement. Subsequently, her vital signs became stable.

Administration of aspirin $(100 \mathrm{mg} /$ day $)$ and edoxaban tosilate hydrate (because of the huge plexiform neurofibromas; Lixiana", Daiichi-Sankyo Co. Ltd., Tokyo, Japan, $30 \mathrm{mg} /$ day) was initiated at 24 days after stentgraft placement, which was changed to aspirin $(100 \mathrm{mg} /$ day) and warfarin potassium ( $3 \mathrm{mg} /$ day) at 31 days after treatment. Excellent patency of the stent graft was confirmed on follow-up contrast CT at 28 days after treatment (Fig. 4d). She was discharged at 56 days after treatment.

\section{Discussion and conclusion}

NF1 is one of the most frequent autosomal-dominant inherited disorders, with an incidence of 1 in 3000 births (Falcone et al. 2010). There is a great variety of 


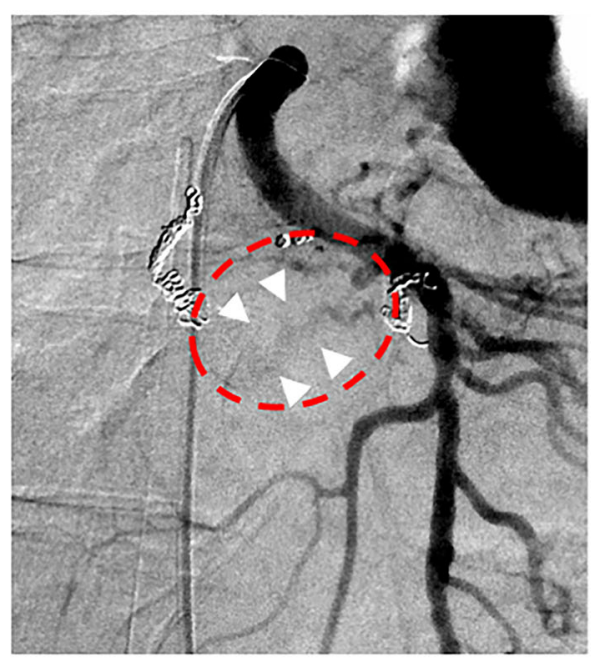

a.

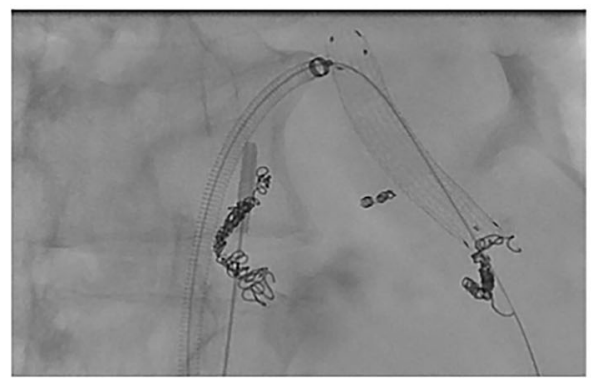

b.

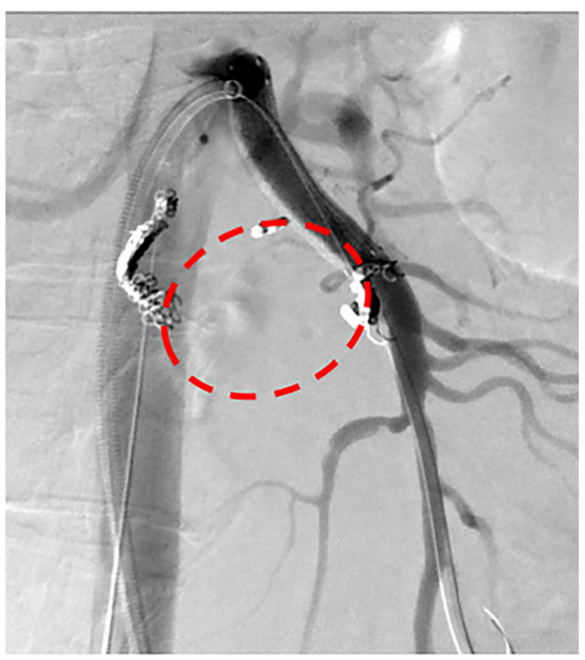

C.

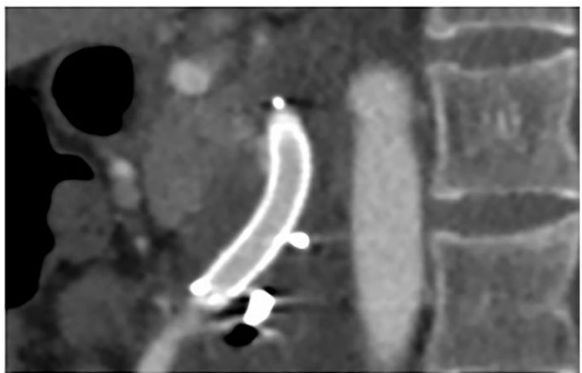

d.

Fig. 4 SMA angiography at stent-graft placement and postoperative computed tomography (CT) (a) SMA angiogram, obtained after TAE, showing continued extravasation (white arrowhead in the red circle) without a definite causal artery. b Digital angiogram obtained after stentgraft placement in the SMA trunk (Viabahn, $7 \mathrm{~mm} \times 5 \mathrm{~cm}$ ). c SMA angiogram, obtained after stent-graft placement, showing the complete disappearance of extravasation (red circle). $\mathbf{d}$ Contrast-enhanced CT image, obtained at day 28 after treatment, confirming good patency of the stent graft

manifestations in NF1, involving mesenchymal tissue in musculoskeletal and cardiovascular systems (Hinsch et al. 2008). Although the estimated prevalence of NF-V has been reported as $0.4-6.4 \%$, the actual frequency is unknown, as most patients with NF-V are asymptomatic throughout life. According to an autopsy series of patients with NF1 who died of other causes, vasculopathy was reported in $44 \%$ of cases (Salyer and Salyer 1974). Therefore, with the inclusion of asymptomatic NF-V, the frequency of vasculopathy in patients with NF1 may be higher than previously reported.

Patients with NF1 have a decreased life expectancy, by 15 years, compared to that of the general population. Malignant neoplasms are the most common cause of death in NF1, followed by vasculopathy (Rasmussen et al. 2001). Cardiovascular disease, haemorrhage, and embolism associated with vasculopathy are frequent causes of death in adult patients with NF1 (Zoller et al. 1995). NF-V includes aneurysms, aneurysmal dilatation, stenosis, rupture, and arteriovenous malformations (D'Errico et al. 2018; Hinsch et al. 2008; Falcone et al. 2010). Among these, aneurysmal dilatation is the most common form of vasculopathy (D'Errico et al. 2018). Additionally, the involvement of multiple vessels is a common characteristic of NF-V (Friedman et al. 2002). In fact, in the present case, multiple aneurysmal dilatations and multiple splenic aneurysms were observed on CT.

Fatal haemorrhaging due to the spontaneous rupture of extracranial arteries in NF1 has been reported, with thoracic vessels in most cases (Ishizu et al. 2006; Bargiela et al. 2018). In contrast, there are only 5 reported cases of ruptured visceral arteries, with SMA, renal artery, and gastroduodenal artery involvement (Huffman et al. 1996; Hinsch et al. 2008; Bargiela et al. 2018); none involved the spontaneous rupture of the PAA.

NF-V is usually described as mesodermal dysplasia or fibromuscular hyperplasia (Hinsch et al. 2008) (Raborn 
et al. 2020). Mutations in the NF1 gene result in decreased neurofibromin, with subsequent proliferation of endothelial and smooth muscle cells in the arteries and veins (Hung et al. 2012). As a result, the vascular tissue is fragile in patients with NF1 (Aizawa et al. 2010). Moreover, the following have been reported as causes of rupture in patients with NF1: 1) the direct invasion of neurofibromas; 2) compression of the vasa vasorum by neurofibromas; 3) physical movement (e.g. orthopaedic traction); and 4) pregnancy (Ishizu et al. 2006; Leier et al. 1972).

In the present case, in addition to the aforementioned fragile nature of the arterial vessel, we speculated that the spontaneous rupture of the PAA, rather than an existing aneurysm associated with NF1, might have resulted from a direct invasion of neurofibromas. The pseudoaneurysm involved multiple arteries (ASPDA, AIPDA, and PIPDA), and selective angiography of the AIPDA showed early visualization of the portal vein at the AIPDA. We believe that a minor arterioportal shunt was created when the pseudoaneurysm ruptured, and an arteriovenous malformation did not exist. These findings suggest a sudden rupture due to a direct invasion of neurofibromas, rather than the rupture of an existing aneurysm. In fact, a previous CT scan (performed 7 years before TAE at another hospital; images not shown) showed a soft-tissue density around the SMA and no aneurysm in the PAA. Additionally, coronal short-TI inversion recovery magnetic resonance imaging (MRI) performed before TAE (as follow-up for a meningocele from the lumbar spine to the sacrum at another hospital; images not shown), showed a high-intensity area around the SMA, indicating the presence of neurofibromas. We believe that these findings support our speculation. Additionally, although the possibility that an existing PAA aneurysm had ruptured cannot be completely ruled out, this was considered unlikely, as there was no median arcuate ligament stenosis on celiac angiography and no aneurysm on previous CT images. Even if the present case involved a ruptured PAA aneurysm, it is still of interest, as there are only 2 reported cases of ruptured pancreaticoduodenal artery aneurysm associated with NF1 (Serleth et al. 1998; Fukushima et al. 2020).

To our best knowledge, the present case is first reported case of intraperitoneal bleeding due to spontaneous PAA rupture associated with NF1, successfully treated by TAE combined with stent-graft placement and IABO. Endovascular management is safe and effective at all ages, even in haemodynamically unstable patients with NF1 (Bargiela et al. 2018). Vital signs in the present case were unstable; therefore, we used IABO, which is effective in non-traumatic, as well as traumatic, intra-abdominal haemorrhage (Hoehn et al. 2019). However, her vital signs remained unstable under IABO after
ASPDA embolization. Therefore, we controlled the flow of the SMA at the area of major extravasation with a compliant balloon. After this, her vital signs became stable, and endovascular treatment of the SMA system (AIPDA and PIPDA) could be performed.

In cases of neurofibromatosis-associated aneurysms, endovascular treatment with coiling is the most commonly used technique (55/66 cases; $83.3 \%$ ), followed by stent-graft placement (10/66 cases; 15.2\%) (Bargiela et al. 2018). Furthermore, in half of the latter cases, as well as in the present case, coil embolization was performed in addition to stent-graft placement. Thus, this treatment method should be considered in cases of rupture. We used a steerable microcatheter due to the steep angles of both the AIPDA and PIPDA, resulting in a successful catheterization. This device, which has a remotecontrolled flexible tip, manipulated using a dial in the handgrip, is effective in the quick catheterization of such challenging vessel cases (Soyama et al. 2017).

Surgical control of haemorrhages in NF1 is reportedly difficult, due to the high fragility of the involved vessels with this disease (Hung et al. 2012; Aizawa et al. 2010). Therefore, if an arterial rupture is suspected, endovascular therapy should be considered (Hung et al. 2012).

Currently, there are no standard recommendations for routine follow up in NF-V. Vascular complications, including spontaneous rupture, can occur over time (Hung et al. 2012). A spontaneous arterial rupture is rare, but can sometimes be fatal (Roberts et al. 2019). Therefore, careful observation with imaging is necessary (Bargiela et al. 2018). In the present case, we planned to perform regular CT examinations once a year. Additionally, as she underwent stent-graft placement, there is a risk of SMA thrombotic occlusion; thus, lifelong antiplatelet therapy with aspirin $(100 \mathrm{mg} /$ day $)$ is necessary. Good long-term stent patency was reported in 9 of 11 cases (mean follow-up, 28 months), including 1 case with stent placement in the SMA and antiplatelet therapy $(100 \mathrm{mg} /$ day aspirin) (Kunzle et al. 2013).

Based on the present case, PAA rupture should be considered as one of the potential conditions of NF-V. Furthermore, spontaneous PAA rupture associated with NF1 can be successfully treated by TAE combined with stent-graft placement and partial IABO.

\section{Abbreviations}

AIPDA: Anterior inferior pancreaticoduodenal artery; ASPDA: Anterior superior pancreaticoduodenal artery; CT: Computed tomography; IABO: Intra-aortic balloon occlusion; MRI: Magnetic resonance imaging; NF1: Neurofibromatosis type 1; NF-V: NF1 vasculopathy; PAA: Pancreatic arcade artery;

PIPDA: Posterior inferior pancreaticoduodenal artery; SMA: Superior

mesenteric artery; TAE: Transcatheter arterial embolization

\section{Acknowledgements}

We are deeply grateful to Dr. Naoya Kinota and Dr. Yusuke Sakuhara for their valuable advice concerning this case report. 


\section{Authors' contributions}

RM and DA, TK performed the endovascular therapy. RM wrote and reviewed the manuscript, DA and TS, YY, TY, KK reviewed the case report manuscript. All authors read and approved the final manuscript.

\section{Funding}

The authors received no specific funding for this work."

\section{Availability of data and materials}

Not applicable.

\section{Ethics approval and consent to participate}

Not applicable.

\section{Consent for publication}

Written informed consent was obtained from the patient for publication of this case report and any accompanying images.

\section{Competing interests}

The authors declare that they have no competing interests.

\section{Author details}

'Department of Diagnostic and Interventional Radiology, Hokkaido University Hospital, Sapporo, Japan. ${ }^{2}$ Department of Diagnostic Radiology, National Hospital Organization Hokkaido Cancer Center, Sapporo, Japan. ${ }^{3}$ Department of Diagnostic Imaging, Hokkaido University Graduate School Medicine, Hokkaido University, Sapporo, Japan.

Received: 7 March 2020 Accepted: 27 May 2020

Published online: 26 July 2020

\section{References}

Aizawa K, Iwashita C, Saito T, Misawa Y (2010) Spontaneous rupture of an intercostal artery in a patient with neurofibromatosis type 1. Interact Cardiovasc Thorac Surg 10:128-130

Bargiela D, Verkerk MM, Wee I, Welman K, Ng E, Choong A (2018) The endovascular management of neurofibromatosis-associated aneurysms: a systematic review. Eur J Radiol 100:66-75

D'Errico S, Martelloni M, Cafarelli FP, Guglielmi G (2018) Neurofibromatosis 1 and massive hemothorax: a fatal combination. Forensic Sci Med Pathol 14:377380

Falcone JL, Go MR, Baril DT, Oakley GJ, Makaroun MS, Chaer RA (2010) Vascular wall invasion in neurofibromatosis-induced aortic rupture. Vasc Endovasc Surg 44:52-55

Friedman JM, Arbiser J, Epstein JA, Gutmann DH, Huot SJ, Lin AE, McManus B, Korf BR (2002) Cardiovascular disease in neurofibromatosis 1: report of the NF1 cardiovascular task force. Genet Med 4:105-111

Fukushima N, Aoki H, Takenaga S, Morikawa K, Ogawa M, Yanaga K (2020) Ruptured visceral artery aneurysms in a patient of neurofibromatosis type 1 (NF-1) successfully treated by endovascular treatment. Surg Case Rep 6:18

Hinsch N, Kriener S, Ritter RG, Holzer K (2008) Fatal haemorrhage due to extensive fragility of medium- and large-sized arteries and veins in a young patient w ith neurofibromatosis 1. Cardiovasc Pathol 17:108-112

Hoehn MR, Hansraj NZ, Pasley AM, Brenner M, Cox SR, Pasley JD, Diaz JJ, Scalea T (2019) Resuscitative endovascular balloon occlusion of the aorta for nontraumatic intra-abdominal hemorrhage. Eur J Trauma Emerg Surg 45:713-718

Huffman JL, Gahtan V, Bowers VD, Mills JL (1996) Neurofibromatosis and arterial aneurysms. Am Surg 62:311-314

Hung MC, Yang E, Huang YC, Chang RS (2012) Spontaneous hemorrhage within the neck of a neurofibromatosis type 1 patient. J Emerg Med 43:448-450

Ishizu A, Ooka T, Murakami T, Yoshiki T (2006) Rupture of the thyrocervical trunk branch from the subclavian artery in a patient with neurofibromatosis: a case report. Cardiovasc Pathol 15:153-156

Kunzle S, Glenck M, Puippe G, Schadde E, Mayer D, Pfammatter T (2013) Stentgraft repairs of visceral and renal artery aneurysms are effective and result in long-term patency. J Vasc Interv Radiol 24:989-996

Leier CV, DeWan CJ, Anatasia LF (1972) Fatal hemorrhage as a complication of neurofibromatosis. Vasc Surg 6:98-101

Liang Y, Tong F, Zhang L, Li W, Zhou Y (2016) Sudden death due to rupture of the right internal carotid artery in neurofibromatosis type 1: a case report. Leg Med (Tokyo) 21:33-37
Moerbeek PR, van Buijtenen JM, van den Heuvel B, Hoksbergen AW (2015) Fatal retroperitoneal bleeding caused by neurofibromatosis: a case report and review of the literature. Case Rep Med 2015:965704

Park YJ, Park KM, Oh J, Park HS, Kim JS, Kim YW (2012) Spontaneous aortic rupture in a patient with neurofibromatosis type 1. J Korean Surg Soc 82: 261-265

Raborn J, Mccafferty BJ, Gunn AJ, Moawad S, Mahmoud K, Aal AKA, Saddekni S (2020) Endovascular management of neurofibromatosis type l-associated vasculopathy: a case series and brief review of the literature. Vasc Endovasc Surg 54:182-190

Rasmussen SA, Yang Q, Friedman JM (2001) Mortality in neurofibromatosis 1: an analysis using U.S. death certificates. Am J Hum Genet 68:1110-1118

Roberts K, Fan B, Brightwell R (2019) Spontaneous accessory renal artery aneurysm rupture in a patient with neurofibromatosis type 1: a case report. Vasc Endovasc Surg 53:150-153

Salyer WR, Salyer DC (1974) The vascular lesions of neurofibromatosis. Angiology 25:510-519

Serleth HJ, Cogbill TH, Gundersen SB 3rd (1998) Ruptured pancreaticoduodenal artery aneurysms and pheochromocytoma in a pregnant patient with neurofibromatosis. Surgery 124:100-102

Soyama T, Yoshida D, Sakuhara Y, Morita R, Abo D, Kudo K (2017) The steerable microcatheter: a new device for selective catheterisation. Cardiovasc Intervent Radiol 40:947-952

Zoller M, Rembeck B, Akesson HO, Angervall L (1995) Life expectancy, mortality and prognostic factors in neurofibromatosis type 1. A twelve-year follow-up of an epidemiological study in Goteborg, Sweden. Acta Derm Venereol 75: $136-140$

\section{Publisher's Note}

Springer Nature remains neutral with regard to jurisdictional claims in published maps and institutional affiliations.

\section{Submit your manuscript to a SpringerOpen ${ }^{\circ}$ journal and benefit from:}

- Convenient online submission

- Rigorous peer review

- Open access: articles freely available online

- High visibility within the field

- Retaining the copyright to your article

Submit your next manuscript at $\boldsymbol{\nabla}$ springeropen.com 